\title{
Perceived Effectiveness of Livestock-Guarding Dogs Placed on Namibian Farms
}

\author{
Laurie L. Marker, ${ }^{1}$ Amy J. Dickman, ${ }^{2}$ and David W. Macdonald ${ }^{3}$ \\ Authors are ${ }^{1}$ Director and ${ }^{2}$ Senior Research Assistant, Cheetah Conservation Fund, PO Box 1755, Otjiwarongo, Namibia; and \\ ${ }^{3}$ Professor and Director, Wildlife Conservation Research Unit, 30 South Parks Road, Oxford, United Kingdom OX1 3PS.
}

\begin{abstract}
Evaluations of 117 livestock-guarding dogs placed on Namibian farms between January 1994 and November 2001 were conducted as part of a study aimed at reducing livestock depredation rates on both commercial and communal farmland. The perceptions of livestock farmers were evaluated in terms of their satisfaction with the guarding dogs, the level of care given to the dogs, and the attentiveness, trustworthiness, and protectiveness of the dogs. Guarding dogs were very successful in terms of reducing livestock losses, with $73 \%$ of responding farmers reporting a large decline in losses since acquisition of a guarding dog, and the same percentage seeing an economic benefit to having the dog. Farmer satisfaction with the dogs was high, with $93 \%$ of farmers willing to recommend the program, and the care given to the dogs was also good. The dogs exhibited high levels of protectiveness and attentiveness, although trustworthiness was relatively low. The level of care provided by farmers was lower for older dogs than for younger dogs, and older dogs appeared to be less trustworthy than young dogs. There were no obvious differences in effectiveness between the sexes, or between dogs placed on communal farms and those on commercial ranches. The majority of dogs exhibited behavioral problems at some stage, particularly chasing game, staying at home, and harassing livestock, but corrective training solved $61 \%$ of the reported problems. We conclude that with the correct training and care, livestock-guarding dogs can be an effective method of livestock protection on Namibian farmlands.
\end{abstract}

\section{Resumen}

Se condujeron evaluaciones con 117 perros guardianes colocados en granjas de Namibia entre Enero de 1994 y Noviembre del 2001, como parte de un estudio encaminado a reducir las tasas de depredación de ganado tanto en granjas comerciales como en granjas comunales. Se evaluaron las percepciones de los granjeros en términos de su satisfacción con los perros guardianes, el nivel de cuidado dado a los perros y la cordialidad, confiabilidad y grado de protección brindada por los perros. Los perros guardianes fueron muy exitosos en términos de reducir las perdidas de ganado, el $73 \%$ de los granjeros respondió que hubo una gran disminución de las perdidas desde la adquisición de los perros guardianes y el mismo porcentaje vio que el tener los perros es un beneficio económico. La satisfacción de los granjeros con los perros fue alta, el $93 \%$ de ellos granjeros están de dispuestos a recomendar el programa y el cuidado proporcionado a los perros fue bueno. Los perros mostraron niveles altos de protección y cordialidad, aunque la confiabilidad fue relativamente baja. El nivel de cuidado dado por los granjeros fue mas bajo para los perros viejos que para los jóvenes y también los perros viejos parecieron ser menos confiables que los jóvenes. No hubo una diferencia obvia en la efectividad entre el sexo del perro o entre los perros colocados en granjas comunales o ranchos comerciales. La mayoría de los perros mostraron problemas de comportamiento en alguna etapa, particularmente en el juego de persecución, su permanencia en casa u hostigando al ganado, pero el entrenamiento correctivo resolvió el $61 \%$ de los problemas reportados. Concluimos que, con el entrenamiento y cuidado correctos, los perros guardianes del ganado pueden ser un método efectivo de protección del ganado en las granjas de Namibia.

Key Words: Anatolian Shepherd, guardian animal, livestock depredation

\section{INTRODUCTION}

Successful livestock farming clearly involves efficient stock management, including the implementation of effective strategies to reduce losses wherever possible. Livestock losses can have a severe economic impact on farmers, especially in poorer farming regions of the world (Oli et al. 1994; Hussain 2003),

Research was funded in part by the African Wild life Foundation, the Cheetah Conservation Fund-USA, the Cincinnati Zoo, Earthwatch Institute, the Weeden Foundation, the WILD Foundation, and the World Wildlife Fund South Africa Green Trust.

Correspondence: Laurie Marker, Cheetah Conservation Fund, P0 Box 1755, Otjiwarongo, Namibia. Email: cheetah@iway.na

Manuscript received 27 September 2003; manuscript accepted 19 February 2005. and many losses are attributed to predators (Andelt 1992; Andelt 1999). A wide variety of techniques aimed at reducing livestock depredation have been developed, such as the use of electric fencing, lethal predator control, toxic collars, disruptive stimuli, and various aversive techniques (Shivik et al. 2003; Treves and Karanth 2003), and such strategies have been employed on farmland with varying degrees of success (Ellins et al. 1977; Forthman Quick et al. 1985; Veeramani et al. 1996). However, such methods are often relatively costly in terms of equipment, technology, and/or labor, and these costs can be prohibitive in many situations, especially in developing countries (Treves and Karanth 2003). Refining practical, lowtechnology approaches to reducing livestock depredation and gaining a better understanding of factors affecting the success of 
such methods will have important implications for farmers, both in developing countries and elsewhere.

Moreover, many of the traditional approaches to reducing livestock depredation rely on removing or excluding predators from the system concerned (Rasmussen 1999; Treves and Karanth 2003), and this has conservation implications in areas where predators themselves are threatened (Meriggi and Lovari 1996; Mishra 1997). This is the situation in Namibia, where cheetahs (Acinonyx jubatus, Schreber), despite having undergone a serious population decline over the past 20 years, are still legally removed from farms in attempts by farmers to reduce levels of livestock depredation (Marker et al. 2003). There is a strong relationship between levels of livestock loss to predators and the removal of those predators from the ecosystem (Ogada et al. 2003; Shivik et al. 2003), so implementing effective methods of reducing livestock depredation may also reduce the number of predators removed from privately owned land (Landry 2001). Although this was not directly measured during this study, developing an effective method to reduce livestock depredation on farmlands where large predators are endemic could have important implications for efficiently managing livestock without needing to resort to predator elimination. As well as having clear economic benefits for the farmers concerned in terms of reduced losses, developing such a method would have evident conservation benefits in terms of facilitating the coexistence of people and large carnivores outside protected areas.

One approach, which combines the advantages of requiring no technological expertise, being relatively inexpensive, and allowing predators to remain part of the system, involves the use of livestock-guarding dogs, which have long been used in Europe to reduce livestock losses from large carnivores (Laurans 1975; Sims and Dawydiak 1990). These dogs are large, have a threatening bark, and show attentive, trustworthy, and protective behavior to the livestock with which they were raised. They are not bred to herd stock, but place themselves between the stock and the threat and bark loudly. If provoked, the dog will attack, but often its presence alone deters predators. The use of such guarding dogs has been extended successfully to commercial ranches in North America but, to date, there has been no published study of their efficacy at reducing livestock depredation on African rangeland. Moreover, while previous published studies have examined how effective guarding dogs can be at reducing depredation caused primarily by canids and ursids (Linhart et al. 1979; Andelt 1992), this is the first longterm study of their efficiency at reducing losses in an area where large felids (namely cheetahs and leopards, Panthera pardus) are the main predators threatening stock.

The Cheetah Conservation Fund (CCF) began a livestockguarding dog program in 1994, using the Anatolian Shepherd, a Turkish breed used for over 6000 years to protect livestock. The objectives were to evaluate the effectiveness of these dogs in terms of reducing livestock losses on both commercial ranches and communal farms in Namibia, and to investigate which factors seemed to influence their success. This manuscript presents information regarding the satisfaction of owners with their livestock-guarding dogs, the perceived effectiveness of the dogs, and factors that appeared to influence performance. This information could help farm managers in a wide variety of situations where livestock depredation poses a significant threat to their livelihoods.

\section{METHODS}

The commercial ranches in the study ranged in size from 5000 20000 ha (average $9000 \mathrm{ha}$ ) and were primarily bushveld with grasslands suitable for livestock or game. The area was predominately thornbush savanna (Joubert and Mostert 1975) that was increasingly subject to bush encroachment as a result of livestock overgrazing (Marker 2002). The arid environment and the encroached bush meant that farmers had to use extensive grazing methods, allowing their stock to range over large areas in the day before bringing them into a corral at night. The commercial ranches supported high numbers of free-ranging game (Joubert and Mostert 1975).

Management practices in the eastern communal land of Namibia differed from those of the commercial ranches due to the high density of resettled people living on marginal land (Katzoa et al. 1993). There was an average of 20 homesteads per village and 100 people per village. Each homestead had its own herds of stock, and each farmer had his own management system. The majority of communal farmers used an open grazing system with no fences except a livestock corral near the homestead. Wildlife on the eastern communal lands occurs at low density, and the land has deteriorated through the communal farming system (Katzoa et al. 1993), changing from open savanna to thornbush savanna (Joubert and Mostert 1975).

This study was started in 1994 with 10 Anatolian Shepherds from the Birinci line that were imported to Namibia from the United States; 145 dogs were subsequently bred on selected farms in Namibia in working environments. Two additional males were later imported for breeding purposes. All the dogs bred in-country were kept with their mothers for 6-8 weeks, in a corral with livestock in the vicinity of the puppies.

Farmers interested in receiving a livestock-guarding dog were asked to complete a potential owner's questionnaire to allow us to select the most appropriate farms on which to place dogs, with the aim of placing dogs on farms where livestock losses to predators occurred. Upon dog placement, farmers were given guidelines on recommended care and training, told what they should expect from the dog, and encouraged to contact us if they had any subsequent problems or questions. Dogs were periodically monitored throughout their lives and regular visits were made to the farms to check on the condition of the dogs and provide advice. Placements began on commercial ranches in January 1994 and on communal farms in February 1997, and were ongoing at the time of analysis.

The performance of the dogs was evaluated on the basis of 117 questionnaires conducted on 117 individual dogs, aged between 2 months and 86 months, between August 1995 and January 2002. The first goal was to determine a farmer satisfaction score, based on whether the farmer thought that the dog was performing well, whether it was behaving as expected, whether there was a perceived economic benefit to having the dog, and whether the farmer would recommend the program as a method of reducing livestock loss. Levels of livestock loss experienced were categorized as follows: no losses $(<1$ head of livestock lost annually); low losses (1-4 head of livestock lost annually); medium losses (5-9 head of livestock lost annually); and high losses ( $\geq 10$ head of livestock lost annually). Changes in the level of loss from one category to an adjacent category 
Table 1. Age group at time of assessment and sex of the 117 livestockguarding dogs evaluated during this study. All dogs were actively working as guardians on either commercial ranches or communal farms in Namibia at the time of evaluation.

\begin{tabular}{lcccccccc}
\hline & \multicolumn{3}{c}{ Commercial } & & \multicolumn{3}{c}{ Communal } \\
\cline { 2 - 4 } \cline { 7 - 9 } & $\begin{array}{c}\text { Puppy } \\
(<1 \mathrm{y})\end{array}$ & $\begin{array}{c}\text { Juvenile } \\
(1-2 \mathrm{y})\end{array}$ & $\begin{array}{c}\text { Adult } \\
(\geq 2 \mathrm{y})\end{array}$ & \begin{tabular}{c} 
Unknown \\
\cline { 7 - 9 }
\end{tabular} & $\begin{array}{c}\text { Puppy } \\
(<1 \mathrm{y})\end{array}$ & $\begin{array}{c}\text { Juvenile } \\
(1-2 \mathrm{y})\end{array}$ & $\begin{array}{c}\text { Adult } \\
(\geq 2 \mathrm{y})\end{array}$ \\
\hline Female & 16 & 10 & 15 & 4 & 9 & 0 & 1 \\
Male & 11 & 10 & 14 & 2 & 17 & 3 & 5 \\
Total & 27 & 20 & 29 & 6 & 26 & 3 & 6 \\
\hline
\end{tabular}

(e.g., from medium losses to low losses) were categorized as slight changes, while changes that spanned 2 or more categories (e.g., from high losses to low or no losses) were defined as large changes in levels of livestock loss.

In terms of dog behavior, 3 main indicators of performance were calculated: attentiveness, trustworthiness, and protectiveness, following Coppinger and Coppinger (1980). Respondents evaluated a dog's attentiveness by examining whether the dog stayed with the herd all the time, whether it bonded with the livestock, if it appeared to be a part of the flock, and if it showed suitably attentive and investigative behaviors towards the flock. Trustworthiness was evaluated from questions concerning whether the dog showed the expected guarding-dog behaviors, such as submission towards the stock, and whether it exhibited undesirable behavior such as playing with and chasing the stock. Assessing protectiveness involved examining whether the dog showed protective behavior, showed a capability to guard effectively, and displayed an aggressive reaction towards intruders and investigating the level of impact that the dog had on stock losses since joining the herd. A care score, to determine how much care was provided to the dog by the farmer, was also calculated from questions regarding the diet given, frequency of feeding, healthcare provided, and access to water. Responses to all questions were assigned numerical codes on a 5-point scale, ranging from +2 (excellent) to -2 (very poor), and the score for that trait was converted into a number between 0 and 1, with 0 being the minimum possible score, showing no evidence of that trait at all, and 1 being the maximum possible score attainable. Not all the farmers answered all the questions, so there is some variation in the number of respondents for different variables.

Puppy aptitude tests were conducted on 39 of the puppies (23 males and 16 females) from 3 litters born since 1998, all of which later entered the program as working dogs. These tests were conducted at 6-9 weeks of age and each puppy was scored using the protocol defined by Sims and Dawydiak (1990). A score of 1 indicated submissive behavior, 2 indicated intermediate behavior, and 3 indicated dominant behavior, and these scores were examined in relation to the later performance of the working dog.

Statistical analyses were performed using SPSS version 10.0 software (SPSS Inc., Chicago, IL). Normality of variables was tested using the Kolmogorov-Smirnov and Shapiro-Wilk tests; where there was significant deviation from normality, nonparametric tests were used. These nonparametric tests included the Kruskal-Wallis and Mann-Whitney U tests; departures from expected ratios were analyzed using chi-squared tests.

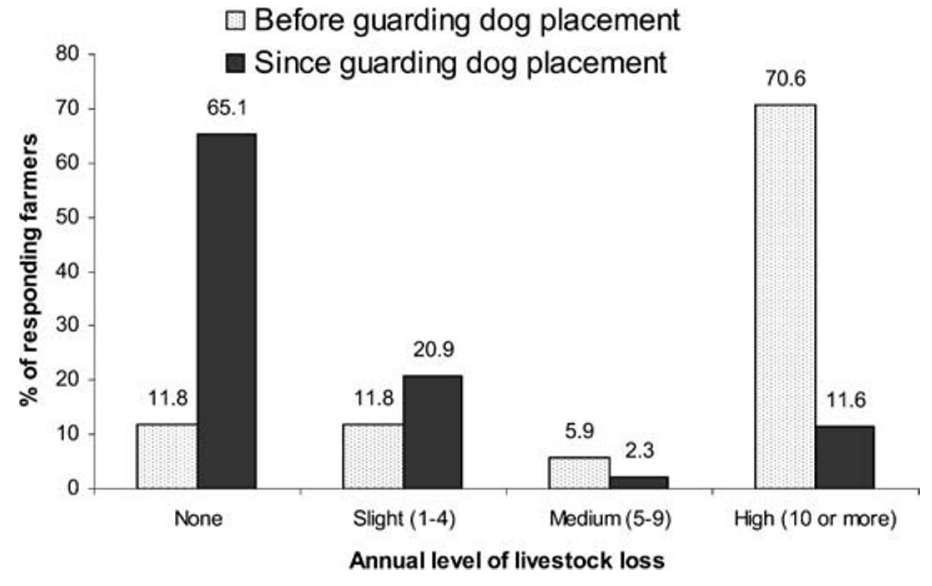

Figure 1. Change in the level of livestock loss reported by Namibian farmers, both communal and commercial, since acquiring a livestockguarding dog.

For normally distributed variables, means analyses were conducted using the independent samples $t$-test, using Levene's test to determine the equality of variances. Correlations were investigated using Spearman's correlation coefficient unless there was known to be a confounding variable, such as age of the dog, in which case partial correlations were calculated to control for the effects of that variable. All tests were 2-tailed unless otherwise stated.

\section{RESULTS}

During the study, 12 dogs were imported and 145 were born in 15 litters to 6 sires and 7 dams. Overall, 143 were placed as guarding dogs and 65 died. The sample population on which the 117 questionnaires were conducted is shown in Table 1.

\section{Changes in the Level of Livestock Loss}

The dogs appeared to have a substantial impact on the level of livestock losses, as the majority of the farmers had high levels of losses before getting a dog, but after guarding-dog placement almost $70 \%$ of farmers reported that they suffered no losses (Fig. 1).

Overall, $73 \%$ of responding farmers reported a large decrease in the level of livestock loss after receiving a livestockguarding dog. The change in loss was significantly greater on communal farms than on commercial ranches $(z=-2.10$, $P=0.036$ ), with all of the responding communal farmers reporting a large decrease in the level of livestock loss since placement of the dog (Fig. 2).

\section{Farmer Satisfaction}

The level of farmer satisfaction was high, with an overall mean score of 0.77 . Farmer expectations of the program were usually met, with the majority of respondents $(78.7 \%)$ reporting that the dog behaved as expected, and almost three-quarters $(69.8 \%, n=44)$ seeing an economic benefit to having a guarding dog. In addition, $68.7 \%$ of responding farmers reported their dog's performance as being either good or excellent. Seventy-five percent of respondents who also used herders said that the guarding dog was working well with the herder, $83.3 \%$ 


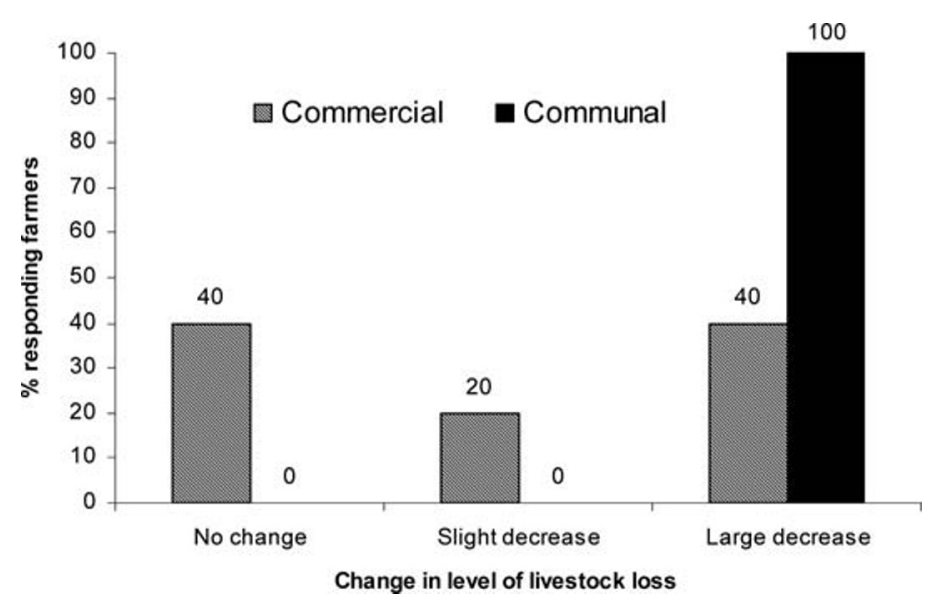

Figure 2. Magnitude of the change in level of livestock loss reported by commercial and communal Namibian farmers since acquiring a livestock-guarding dog. A slight decrease was defined as changing by 1 category, e.g., from suffering a medium level of loss to a low level of loss, while a large decrease was defined as changing by 2 categories or more, e.g., from a high level of loss to low or no losses. Levels of livestock losses were defined as shown in Figure 1, i.e., low losses indicate 1-4 head of stock lost annually; medium losses, 5-9 head of stock lost annually; and high losses, $\geq 10$ head of stock lost annually.

of respondents said that they were confident in the behavior of the dog, and almost all responding farmers $(93 \%, n=56)$ said that they would recommend the program.

\section{Factors Influencing the Success of Dogs}

Age. Age of the dogs at time of evaluation showed a negative relationship with trustworthiness $\left(r_{s}=-0.22, n=104\right.$, $P=0.026)$ and care given by the farmer $\left(r_{s}=-0.26, n=109\right.$, $P=0.006)$, but there was no significant relationship between age of the $\operatorname{dog}$ at time of evaluation and protectiveness $\left(r_{s}=-0.16, n=100, P=0.108\right)$, attentiveness $\left(r_{s}=-0.16\right.$, $n=112, P=0.095)$, or farmer satisfaction $\left(r_{s}=0.16, n=81\right.$, $P=0.167)$.

Farm Type. Whether a dog was placed on a commercial ranch or communal farm appeared to have no significant bearing on its performance (Fig. 3). However, placement of dogs on communal farms began later than those on commercial farms, so the guarding dogs on communal farms were significantly younger at the time of the study than those on commercial ranches $(z=-3.90$, $P<0.001)$ and, as shown above, age at time of evaluation had a significant bearing on some aspects of the dogs' performance. To account for this confounding effect of age, performance was compared between farm types for puppies, juvenile, and adult dogs, and the only significant difference once age was accounted for was that farmer satisfaction with puppies was higher on communal than commercial farms $(z=-2.37, P=0.018)$.

Sex. There were no significant differences between the sexes for any of the 3 behavioral traits scored, or for farmer satisfaction or care given by the farmer.

Stock Guarded. Almost half of the respondents (43.4\%) had their dogs guarding herds of goats; of the rest, $31.6 \%$ of the dogs were with mixed flocks and $25 \%$ were with flocks of sheep.

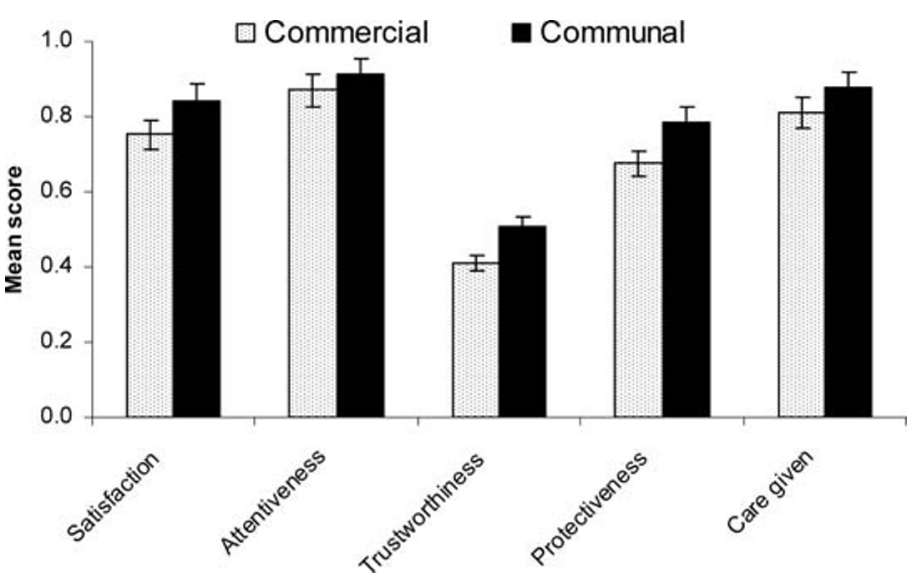

Figure 3. Mean scores for attentiveness, trustworthiness, protectiveness, care given, and farmer satisfaction for livestock-guarding dogs placed on commercial ranches and communal farms in Namibia. Each trait was scored on a scale between 0 and 1, with 0 being the minimum possible score, showing no evidence of that trait at all, and 1 being the maximum possible score attainable. Error bars indicate $95 \%$ confidence intervals.

The performance of dogs placed on communal farms did not change significantly when examined according to stock guarded, but on commercial farms, trustworthiness varied significantly with the type of stock guarded $\left(\chi^{2}=6.38, \mathrm{df}=2, P=0.041\right)$, and attentiveness showed some variation as well $\left(\chi^{2}=6.00\right.$, $\mathrm{df}=2, P=0.050)$. Dogs on commercial farms appeared to be most trustworthy and attentive when placed only with sheep, and least trustworthy when guarding herds composed entirely of goats.

Age at Placement. The age at placement ranged from 0 (in cases where the dog was bred and kept at the same farm) to 2.7 years old, with $93.1 \%$ of the dogs $(n=109)$ placed by 12 weeks of age. Dogs were placed at a younger age as the program progressed $\left(r_{s}=-0.310, n=116, P=0.001\right)$ so the age of the $\mathrm{dog}$ at the time of the survey was controlled for, using a partial correlation procedure, during statistical analyses to remove any confounding effect. Age at placement appeared to have no effect on the resulting attentiveness, trustworthiness, protectiveness, farmer satisfaction, or care given to the dog.

Time With Farmer. Because older dogs were likely to have spent more time with the responding farmer, we controlled for the age of the dog by calculating partial correlations. Time spent with the responding farmer was not related to attentiveness, trustworthiness, protectiveness, farmer satisfaction, or care given to the dog.

Changing Owners. Only a few $(6 \%, n=6)$ of the evaluations involved dogs that had been transferred between owners. Dogs that had been moved between owners were significantly less trustworthy (with a mean trustworthiness score of 0.46) than dogs that had not been transferred (mean trustworthiness score of $0.08 ; z=-2.18, P=0.029$ ), but there was no detectable effect on any of the other parameters measured.

Presence of a Herder. Almost two-thirds of responding farmers $(65 \%, n=26)$ had a herder working with the guarding dog at the time of the survey. Having a herder did 
not affect the performance of the guarding dogs for any of the variables measured.

Presence of Other Dogs. Just over one-third of responding farmers $(36.4 \%, n=24)$ had another dog with the same flock as the livestock-guarding $\mathrm{dog}$, and the presence of these other dogs made no significant difference to the effectiveness of the livestock-guarding dog.

\section{Dog Behavior and Husbandry}

Interactions Between Different Variables. Attentiveness, trustworthiness, protectiveness, and farmer satisfaction were all linked to one another and showed some statistically significant relationships (Table 2). The care given by farmers showed positive relationships with all the behavioral traits, but none of the relationships were statistically significant.

Attentiveness. The dogs evaluated were highly attentive to livestock, with an overall mean attentiveness score of 0.88 . Over two-thirds of the responding farmers $(68.9 \%, n=42)$ claimed that their dogs stayed with the stock 24 hours a day, $95.9 \%(n=71)$ reported that the dog appeared to be part of the stock, and $90.5 \%(n=38)$ stated that the dog had bonded with the stock. In addition, all respondents $(n=22)$ described the $\operatorname{dog}$ as attentive to the stock, $83.3 \%(n=15)$ rated the attentiveness of the $\mathrm{dog}$ as good or excellent, and $100 \%$ $(n=26)$ reported that the dog had been accepted by the stock.

Trustworthiness. The trustworthiness of the dogs showed the most variation, and the mean trustworthiness score, at 0.44 , was substantially lower than the other scores attained. This difference reflected the fact that $25.1 \%(n=11)$ of farmers reporting problems said that their dogs showed a tendency to chase, play with, or bite the livestock (see 'Behavioral Problems,' below). Despite this tendency, almost three-quarters of responding farmers $(72.7 \%, n=32)$ reported that their dog did show submissive behavior towards the stock.

Protectiveness. The dogs scored highly on protectiveness, with an average score of 0.71 . Almost $80 \%$ of responding farmers $(79.5 \%, n=31)$ reported seeing effective guarding behavior such as barking at or confronting predators, with $10.3 \%(n=4)$ not being sure. Nearly half $(43.1 \%, n=25)$ of the farmers rated their dog's protectiveness as excellent, with a further $36.1 \%(n=21)$ classifying it as good.

Care Given. The care provided to the dogs was very high, with a mean care score of 0.83 . Over three-quarters of the dogs $(76.3 \%, n=58)$ were fed an excellent diet, i.e., given an adequate amount of food that included sufficient protein, as recommended at time of placement. The most common diet was a mixture of maize meal, dog pellets, and milk, which was the option chosen by $19.2 \%(n=14)$ of responding farmers. The next most common diet was as above but supplemented with cooked meat, and this diet was provided in $12 \%(n=12)$ of cases. Only $3.9 \%$ of the farmers $(n=3)$ fed their dogs unsatisfactory or poor diets, for example, plain maize meal with no additional protein, or diets that included raw meat.

Almost all of the dogs $(97.7 \%, n=43)$ were fed at least twice a day and all had water freely available. The high level of care given was reflected in the condition of the dogs: $98.4 \%$
Table 2. Relationships (determined using Spearman's correlations) among scores for attentiveness, trustworthiness, protectiveness, farmer satisfaction, and care provided to the dog for livestockguarding dogs evaluated on Namibian farms.

\begin{tabular}{lcrr}
\hline & $r_{\mathrm{s}}$ & \multicolumn{1}{c}{$P$} & \multicolumn{1}{c}{$n$} \\
\hline Attentiveness \& trustworthiness & 0.22 & 0.022 & 108 \\
Attentiveness \& protectiveness & 0.30 & 0.002 & 104 \\
Attentiveness \& care given & 0.09 & 0.342 & 113 \\
Attentiveness \& farmer satisfaction & 0.43 & $<0.001$ & 84 \\
Trustworthiness \& protectiveness & 0.31 & 0.002 & 97 \\
Trustworthiness \& care given & 0.07 & 0.479 & 107 \\
Trustworthiness \& farmer satisfaction & 0.33 & 0.003 & 77 \\
Protectiveness \& care given & 0.12 & 0.237 & 100 \\
Protectiveness \& farmer satisfaction & 0.48 & $<0.001$ & 72 \\
Care given \& farmer satisfaction & 0.19 & 0.095 & 81 \\
\hline
\end{tabular}

of the dogs $(n=60)$ were classified as being in good or excellent health.

Puppy Aptitude Tests. Puppy aptitude tests were conducted on 39 dogs, all of which were subsequently placed on farms, with a mean age at placement of 9 weeks. Just over one-quarter of the puppies tested $(25.6 \%, n=10)$ were scored as intermediate, with $51.3 \%(n=20)$ scored as dominant, and the remaining $23.1 \%(n=9)$ classified as submissive. Twenty of the puppies tested $(51.3 \%)$ were later placed on commercial farms, $18(46.2 \%)$ were placed on communal farms and 1 was initially placed on a communal farm but was later moved to a commercial farm. When the dogs' working behavior was examined, there were no significant differences regarding trustworthiness, attentiveness, protectiveness, care given to the dog, or farmer satisfaction between the those puppies that had tested as dominant, intermediate, or submissive. There was no significant difference in age at evaluation between the 3 groups of dogs $\left(\chi^{2}=0.69, \mathrm{df}=2, P=0.708\right)$.

\section{Behavioral Problems}

Almost all of the respondents $(94.5 \%, n=69)$ reported having had some sort of behavioral problem with their dog at some stage. The majority of farmers $(69.4 \%, n=43)$ had regular contact with their dogs, which made identifying and correcting behavioral problems easier. Nearly three-quarters of respondents $(71.7 \%, n=33)$ with problems reported them to CCF, although the majority of these $(62.5 \%, n=15)$ waited until some time later rather than reporting them immediately. Seventeen farmers responded to the question regarding methods of correction used, and the majority of these $(76.5 \%, n=13)$ used the methods of correction advocated by CCF. Corrective training was found to be effective in $61 \%$ of cases, and $44 \%$ of respondents $(n=44)$ were having some sort of behavioral problem with their dogs at the time of the survey.

The problems reported at the time of the survey are shown in Figure 4. The most common problem reported overall was chasing game, which was cited in almost half the cases $(45.5 \%$, $n=20)$. Staying at home was also prevalent, being reported in $31.8 \%$ of cases $(n=14)$, while $25.1 \%(n=11)$ of the problems reported involved dogs that were harassing or killing livestock. 


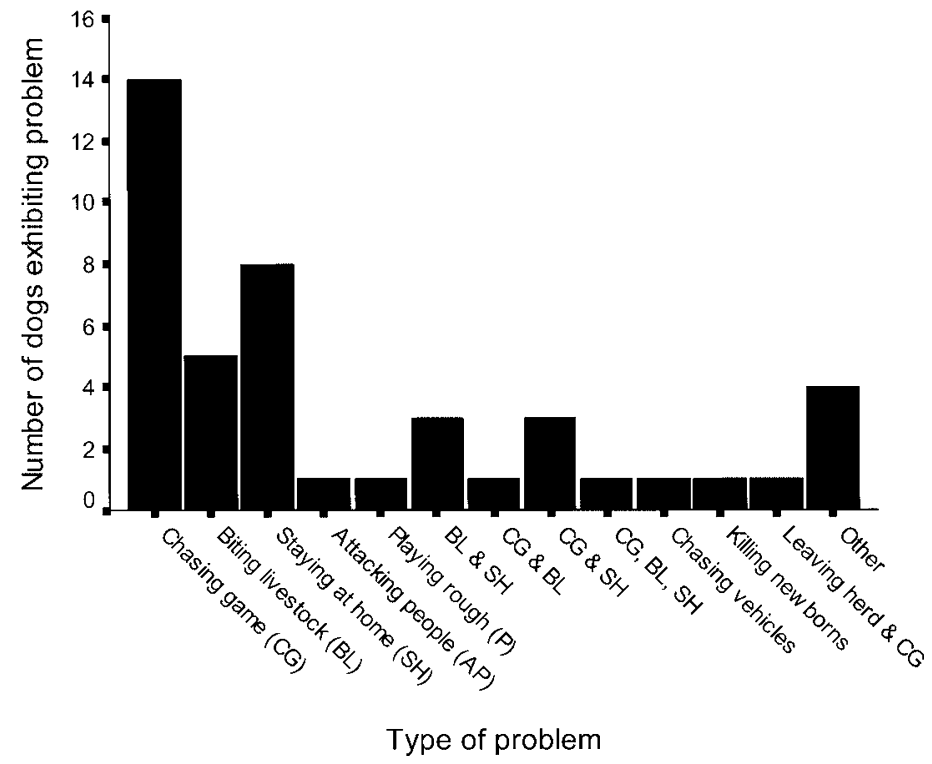

Figure 4. Breakdown of behavioral problems exhibited by the 44 livestock guarding dogs placed on Namibian farms that were reported as having problems at the time of evaluation.

The behavioral problems varied by age group. The most common problem exhibited by dogs under a year old was harassing livestock, which was reported in $51.9 \%(n=6)$ of cases. Chasing game was the most commonly reported problem in both juvenile and adult dogs, being cited in $44.4 \%(n=4)$ and $61.9 \%(n=13)$ of cases respectively.

When the dogs exhibiting behavioral problems were compared to the overall population, there was no significant deviation from the expected sex ratio $\left(\chi^{2}=0.204, \mathrm{df}=1, P=0.652\right)$, and neither transferring dogs $\left(\chi^{2}=2.30, \mathrm{df}=1, P=0.130\right)$ nor farm type $\left(\chi^{2}=1.08, \mathrm{df}=1, P=0.298\right)$ seemed to have a discernible influence on the frequency of problems.

\section{DISCUSSION}

\section{Farmer Satisfaction}

Regardless of the independently calculated performance of the dog, the farmer must perceive a benefit to having a livestockguarding dog for the program to be truly successful. This situation seemed to be the case in this study, with almost $70 \%$ of responding farmers classifying their dog's performance as very good or excellent, and the same proportion recognizing an economic benefit to having a guarding dog. Although this was not quite as positive as the perceptions of farmers in a US study, where $89 \%$ of farmers considered their guarding dogs to be an economic benefit (Green et al. 1984), it still revealed that the technique was viewed positively by Namibian farmers.

\section{Factors Influencing the Success of the Dogs}

Sex. We found no significant differences between the sexes regarding performance. This supported the findings of previous studies (Sims and Dawydiak 1990).

Stock Guarded. This study revealed some variation in effectiveness on commercial ranches depending on the stock guarded.
There was no evident reason for this, as dogs worked in very similar environments regardless of the stock being guarded. A previous study indicated that certain behavioral characteristics of sheep made the guarding dogs more effective (McGrew and Blakesley 1982), but there was no comparison with the behavior of goats, so it is difficult to gauge whether the variation in performance of the dogs in our study was the result of traits of the stock, or of the individual dogs themselves. Guarding dogs have been successfully bonded to a wide variety of species (Sims and Dawydiak 1990), so the management, raising, and training of the dog seem to be more important factors in determining the eventual success of the guardian rather than the species to be guarded.

Age at Placement. There has been much debate about the best age at which to place a dog with the livestock it is assigned to guard. Many authors assert that placing a dog with stock while it is still a young puppy (usually between 6 and 8 weeks old) is a key component of future success (Hansen and Smith 1999), because dogs form strong social attachments to other species at this age (Freedman et al. 1961; Landry 2001). Socialization to people during this stage detracts significantly from the dog's effectiveness (Hansen and Smith 1999), and socialization and bonding is reported to become more difficult after 3 months of age (Landry 2001).

Other studies, however, have shown that dogs introduced to stock later in life can still be effective guardians; for instance, McGrew and Blakesley (1982) reported that the ideal age for exposure of Komondor guarding dogs to livestock was 6-10 months old. We found no significant effect of age at placement on the resultant effectiveness of dogs.

Presence of Other Dogs. Some studies have suggested that the presence of other dogs can cause the livestock-guarding dog to develop undesirable tendencies such as roaming, leaving the flock, and exhibiting aggressive or predatory behavior (Coppinger et al. 1983). In this study, having other dogs working alongside the guarding dog did not have a significant influence on performance. Working effectively despite the presence of other dogs is an advantage, because many farmers had several dogs working with the flock, although the negative impact upon the attentiveness of dogs on commercial farms highlights the need for close monitoring.

\section{Dog Behavior and Husbandry}

Interactions Between Different Variables. The behavioral traits of the guarding dogs, i.e., being attentive, trustworthy, and protective, were not independent, as has been seen in other studies (Coppinger and Smith 1983). Traditionally, the literature has defined a successful livestock guardian as one that scores highly in all 3 areas, although this study shows that even dogs that exhibit behavioral problems and do not score highly on trustworthiness can still be effective in reducing losses.

Attentiveness. A high level of attentiveness to livestock is a key component of effective, successful guarding (Landry 2001). Inattentiveness has been linked both to the high level of mortality in juvenile livestock-guarding dogs and to a reduction in protectiveness (Lorenz et al. 1986). The dogs in this survey were highly attentive relative to those in most previous 
studies. In a 1983 study, Coppinger et al. found that only $37 \%$ of the Anatolians rated in the United States were described as being excellent or good in terms of attentiveness, although high levels of attentiveness were reported by shepherds using the same breeds of dogs in Old World countries.

Trustworthiness. Trustworthiness proved to be the lowestscoring of the behavioral traits, and also showed a large amount of individual variation. Other studies, in the United States, have reported higher degrees of trustworthiness for Anatolians than we found here (Coppinger 1992), although as a breed they have been noted as having a tendency to exhibit untrustworthy behavior (Andelt 1999). Trustworthiness was closely linked to other behavioral traits such as attentiveness and protectiveness, both here (see Table 2) and in other studies (Coppinger et al. 1988).

Livestock-guarding dogs have been selectively bred to lack the ancestral sequence of operative predatory behavior (Landry 2001), and trustworthiness of livestock guardians has been defined as the absence of such behavior (Lorenz and Coppinger 1986). In many cases, however, predatory behaviors are manifested initially as play, and can become reinforced into a problem if not corrected immediately. This type of predatory play behavior was one of the most common problems reported to us, and has also been described in numerous other studies (Linhart et al. 1979). Untrustworthy behavior has been linked to a high-energy diet, with surplus energy being utilized in excessive play behavior and stock harassment (Lorenz and Coppinger 1986). The Namibian dogs, however, despite being fed a relatively low-calorie diet, still exhibited a high frequency of problems associated with excessive playing with the stock, so surplus energy due to diet is unlikely to be the basis for the untrustworthy behavior observed in this study.

Dogs moved between owners were less trustworthy than those that had not been moved, so particularly careful selection and monitoring should be employed when choosing a second home for a livestock-guarding dog. However, it is likely that the dogs that were transferred were less trustworthy to begin with, and that this was why their original owners decided to pass them on, so this lack of trustworthiness many not be an effect of the transfer itself. Overall, however, changing owners had no negative influence on the performance of the dog in terms of protectiveness or farmer satisfaction, indicating that moving dogs between owners can be a workable strategy, and that such dogs can still be successful guardians.

Protectiveness. The dogs studied here proved to be very protective, with the majority of farmers having witnessed effective guarding behavior. The mean protectiveness rating here, with over $80 \%$ of responding farmers in this study rating their dog's protectiveness as good or excellent, was similar to that found by Coppinger et al. in 1988 for various breeds working on ranches in the United States.

The high level of protectiveness was reflected in the large decrease in livestock losses reported by farmers after placement of the dog, a trend that has also been observed in numerous other studies (Coppinger et al. 1988; Andelt 1992; Hansen and Smith 1999). Despite their effectiveness, however, guarding dogs are unlikely to eliminate losses entirely, and for maximal effect should be used as a part of a broader livestock management strategy (McGrew and Blakesley 1982).
Care Given. Overall, the care given to the dogs was high, and this care was probably critical to the success of the program, because although livestock-guarding dogs have long been selectively bred for certain specific behavioral traits, the environment must be adequate in order for these traits to be expressed fully. This interaction between a genetic predisposition to guarding and the local environment has been noted previously (McGrew and Blakesley 1982; Coppinger et al. 1983) and is a very important factor in the development of a useful guarding dog.

Puppy Aptitude Tests. Categorizing the puppies as showing predominantly submissive, intermediate, or dominant behavior at a young age did not prove to be a useful indicator of later success as working dogs, although previous authors have suggested that the more submissive puppies may be the best suited to livestock guarding (Sims and Dawydiak 1990).

\section{Behavioral Problems}

Behavioral problems were very prevalent amongst the dogs placed, although they still acted as effective guardians. Chasing wildlife has been reported in other studies (Coppinger et al. 1988; Hansen and Smith 1999) and may be particularly common in Namibia, as there is a high density of wildlife on the farmlands, and an overzealous guardian may regard them as a threat and learn to chase them. An attentive herder can be very effective in recognizing any such behavior early and teaching the guarding dog that game and other stock animals are not threats.

Harassment of livestock is also a well-reported problem with livestock-guarding dogs, particularly puppies, where it is a damaging manifestation of play behavior (Green et al. 1984; Landry 2001). Young dogs in particular must be closely monitored while with stock to ensure that any rough behavior is noticed immediately and the dog sternly reprimanded. The use of a cumbersome 'dangle stick' attached to a dog's collar has proved effective in curbing the desire to leave the herd and chase wildlife (Sims and Dawydiak 1990).

Use of suggested correction methods proved effective in the majority of cases, although most farmers waited some time before reporting problems. This time lag before seeking advice with behavioral problems is of concern, as rapid action is critical for successful correction.

\section{MANAGEMENT IMPLICATIONS}

Questioning farmers regarding the performance of their dogs is clearly a subjective way of collecting information, as the responses often depend as much on the perception of the farmers as the actual efficacy of the dogs. For this study, however, the perceptions of the people involved were just as important as any objective calculation of performance; therefore, even using these subjective responses, the placement of livestock-guarding dogs proved successful in Namibia.

Effective guarding is challenging in situations where the dog guards stock that ranges unaccompanied over large tracts of land (Hansen and Smith 1999), as is usually the case on the Namibian farmlands. Unlike breeds such as the Komondor, which tends to show site fidelity to a particular area (Linhart 
et al. 1979), the dogs used here proved their efficacy at protecting livestock even in circumstances where they moved long distances on a daily basis. Although guarding dogs do require care, attention, and training, the time spent investing in them is usually outweighed by the time saved in terms of livestock protection and predator control (Andelt 1992), and they have proven to be economic assets (Coppinger et al. 1988).

The decline in livestock losses reported since obtaining a guarding dog, and the high levels of protectiveness, attentiveness, and farmer satisfaction, demonstrate that the placement of these dogs has worked well on Namibian farms. Previous studies have shown that using guarding dogs does not cause predators to leave their territories (Landry 2001), so this strategy has valuable potential in terms of conflict resolution and diminishing livestock losses while still maintaining predators as an integral part of the ecosystem. Using guarding dogs is also likely to be a more effective long-term strategy for reducing losses than techniques such as indiscriminate predator removals, as studies have shown that such removals often do not halt depredation events for long (Stahl et al. 2002). Moreover, many losses attributed to predators are often actually due to other factors such as stock theft (Rasmussen 1999), and guarding dogs have the additional advantage of being able to effectively prevent these losses as well. This study demonstrates that livestock-guarding dogs can be effectively employed in novel environments, e.g., both commercial and communal African farmlands where large felids pose a threat to domestic stock, and have a substantial impact on reducing livestock losses in those situations. Developing a better understanding of this technique and the factors that influence dogs' success will be valuable for farmers in a wide variety of areas where large predators exist alongside domestic stock.

\section{ACKNOWLEDGMENTS}

The authors would like to thank both the Namibian farmers and the Namibian government, particularly the Ministry of Environment and Tourism, without whose support this research would not have been possible. We are very grateful to Dr Ray Coppinger, from Hampshire College in Amherst, Massachusetts, for his early interest and support of the project and for bringing the original Anatolian Shepherds to Namibia, and to the Birinci kennels for the donation of the original dogs. We are also grateful to the team of CCF staff and volunteers, and the 2 anonymous reviewers.

\section{LITERATURE CITED}

Andelt, W. F. 1992. Effectiveness of livestock guarding dogs for reducing predation on domestic sheep. Wildlife Society Bulletin 20:55-62.

ANDELT, W. F. 1999. Relative effectiveness of guarding-dog breeds to deter predation on domestic sheep in Colorado. Wildlife Society Bulletin 27:706-714.

CoppingeR, L. 1992. Dog performance report 1991. DogLog 2:3-5.

Coppinger, R., and L. Coppinger. 1980. Livestock-guarding dogs: an Old World solution to an age-old problem. Country Journal 7:68-77.

Coppinger, R., L. Coppinger, G. Langeloh, L. Gettler, and J. Lorenz. 1988. A decade of use of livestock guarding dogs. In: A. C. Crabb and R. E. Marsh [eds.] Proceedings of Vertebrate Pest Conference 1986; Monterey, CA. University of California, Davis. p. 209-214.

Coppinger, R., J. Lorenz, J. Glendinning, and P. Pinardi. 1983. Attentiveness of guarding dogs for reducing predation on domestic sheep. Journal of Range Management 36:275-279.

Coppinger, R. P., and C. K. Smith. 1983. The domestication of evolution. Environmental Conservation 10.
Ellins, S. R., S. M. Catalano, and S. A. Schechinger. 1977. Conditioned taste aversion: a field application to coyote predation on sheep. Behavioral Biology 20:91-95.

Forthman Quick, D. L., C. Gustavson, and K. W. Rusiniak. 1985. Coyote control and taste aversion. Appetite 6:253-264.

Freedman, D. G., J. A. King, and 0. Elliot. 1961. Critical period in the social development of dogs. Science 133:1016-1017.

Green, J. S., R. A. Woodruff, and T. A. Tueller. 1984. Livestock guarding dogs for predator control: costs benefits and practicality. Wildlife Society Bulletin 12:44-50.

Hansen, I., AND M. E. Smith. 1999. Livestock-guarding dogs in Norway part II: different working regimes. Journal of Range Management 52:312-316.

Hussain, S. 2003. The status of the snow leopard in Pakistan and its conflict with local farmers. Oryx 37:26-33.

Joubert, E., AND P. K. N. Mostert. 1975. Distribution patterns and status of some mammals in South West Africa. Madoqua 9.

Katzoa, J., M. Nangolo, B. Okahan, H. Kateman, E. E. van Starten, and D. H. Kait. 1993. Understanding history grade 10. Windhoek, Namibia: Longman. $158 \mathrm{p}$.

LANDRY, J.-M. 2001. The guard dog: protecting livestock and large carnivores. In: R. Field, R. J. Warren, H. Okarma, and P. R. Sievert [eds.]. Wildlife, land, and people: Priorities for the 21st century. Bethesda, MD: The Wildlife Society. $p$. 209-212.

LaURANS, R. 1975. Sheep guarding and conducting dogs. Ethnozootechnie 12: $15-18$.

Linhart, S. B., R. T. Sterner, T. C. Carrigan, and D. R. Henne. 1979. Komondor guard dogs reduce sheep losses to coyotes: a preliminary evaluation. Journal of Range Management 32:238-241.

LoRENZ, J. R., AND L. CopPInger. 1986. Raising and training a livestock-guarding dog. Corvallis, OR: Oregon State University Extension. Circular 1238. 31 p.

Lorenz, J. R., R. P. Coppinger, and M. R. Sutherland. 1986. Causes and economic effects of mortality in livestock guarding dogs. Journal of Range Management 39:293-295.

MarkeR, L., 2002. Aspects of Nambian Cheetah (Acinonyx jubatus) Biology, Ecology, and Conservation Strategies [PhD Thesis]. Department of Zoology, University of Oxford.

Marker, L., A. J. Dickman, M. G. L. Mills, and D. W. Macdonald. 2003. Aspects of the management of cheetahs trapped on Nambian farmlands. Biological Conservation 114(3):401-412.

McGrew, J. C., AND C. S. BLAKESLEY. 1982. How Komondor dogs reduce sheep losses to coyotes. Journal of Range Management 35:693-696.

MerigGI, A., AND S. Lovari. 1996. A review of wolf predation in southern Europe: does the wolf prefer wild prey to livestock? Journal of Applied Ecology 33: 1561-1571.

MishRA, C. 1997. Livestock depredation by large carnivores in the Indian transHimalaya: conflict perceptions and conservation prospects. Environmental Conservation 24:338-343.

Ogada, M. 0., R. Woodroffe, N. 0. Oguge, and L. G. Frank. 2003. Limiting depredation by African carnivores: the role of livestock husbandry. Conservation Biology 17:1521-1530.

Olı, M. K., I. R. TayloR, and M. E. Rogers. 1994. Snow leopard Panthera uncia predation of livestock: an assessment of local perceptions in the Annapurna conservation area, Nepal. Biological Conservation 68:63-68.

RASMUSSEN, G. S. A. 1999. Livestock predation by the painted hunting dog Lycaon pictus in a cattle ranching region of Zimbabwe: a case study. Biological Conservation 88:133-139.

Shivik, J. A., A. Treves, and P. Callahan. 2003. Nonlethal techniques for managing predation: primary and secondary repellents. Conservation Biology 17: 1531-1537.

Sims, D. E., AND O. Dawydiak. 1990. Livestock protection dogs: selection, care and training. Centreville, AL: OTR Publications. $128 \mathrm{p}$.

Stahl, P., J. M. Vandel, S. Ruette, L. Coat, Y. Coat, and L. Balestra. 2002. Factors affecting lynx predation on sheep in the French Jura. Journal of Applied Ecology 39:204-216.

Treves, A., and U. Karanth. 2003. Human-carnivore conflict and perspectives on carnivore management worldwide. Conservation Biology 17:1491-1499.

Veeramani, A., E. A. Jayson, and P. S. Easa. 1996. Man-wildlife conflict: cattle lifting and human casualties in Kerala. Indian Forester 122:897-902. 